\title{
The effectiveness of rapid sequence intubation (RSI) versus non-RSI in emergency department: an analysis of multicenter prospective observational study
}

\author{
Masashi Okubo ${ }^{1 *}$, Koichiro Gibo ${ }^{2}$, Yusuke Hagiwara ${ }^{3}$, Yukiko Nakayama ${ }^{4}, K_{\text {Kohei Hasegawa }}^{5}$ and On behalf of the
} Japanese Emergency Medicine Network Investigators

\begin{abstract}
Background: Although rapid sequence intubation (RSI) is the method of choice in emergency department (ED) airway management, data to support the use of RSI remain scarce. We sought to compare the effectiveness of airway management between RSI and non-RSI (intubation with sedative agents only or without medications) in the ED.

Methods: Secondary analysis of the data from a multicenter prospective observational registry at 13 Japanese EDs. All non-cardiac-arrest patients who underwent intubation with RSI or non-RSI were included for the analysis. Outcomes of interest were the success rate of intubation and intubation-related complications.

Results: Of 2365 eligible patients, 761 (32\%) underwent intubations with RSI and 1,604 (68\%) with non-RSI. Intubations with RSI had a higher success rate on the first attempt compared to those with non-RSI (73 vs. 63\%; $P<0.0001)$. By contrast, the complication rates did not differ significantly between RSI and non-RSI groups (12 vs. 13\%; $P=0.59$ ). After adjusting for age, sex, estimated weight, principal indication, device, specialties and training level of the intubator, and clustering of patients within EDs, intubation with RSI was associated with a significantly higher success rate on the first attempt $(\mathrm{OR}, 2.3 ; 95 \% \mathrm{Cl}, 1.8-2.9 ; \mathrm{P}<0.0001)$ while that with $\mathrm{RSI}$ was not associated with the risk of complications $(\mathrm{OR}$, $0.9 ; 95 \% \mathrm{Cl}, 0.6-1.2 ; P=0.31)$.
\end{abstract}

Conclusions: In this large multicenter study of ED airway management, we found that intubation with RSI was independently associated with a higher success rate on the first attempt but not with the risk of complications.

Keywords: Airway management, Intubation, Rapid sequence intubation, Intubation success, Complications of intubation, Resuscitation, Emergency department

\section{Background}

Intubation is a critical procedure performed in emergency departments (EDs). Rapid sequence intubation (RSI) is the most commonly used method of ED intubation in many nations [1-8]. Previous studies have reported the associations between the use of RSI and highintubation success rates and low complication rates [4, 7-13]. However, their inferences are potentially

\footnotetext{
* Correspondence: masashiokubo914@gmail.com

Presented at the Society for Academic Emergency Medicine Annual Meeting, Chicago, IL, May 2012

'Department of Emergency Medicine, University of Pittsburgh, Iroquois Building Suite 400 A, 3600 Forbes Avenue, Pittsburgh, PA 15261, USA Full list of author information is available at the end of the article
}

limited by a lack of a control group [7], small sample sizes $[4,11,12]$, lack of adjustment for potential confounding factors and clustering [8], and limited generalizability (e.g., studies in the operating room settings $[9,10]$, in the prehospital setting [11], in a pediatric population [4], and conducted in a single or two centers $[7,12,13])$. Despite its clinical relevance, there have been no large multicenter studies to compare the effectiveness of RSI to non-RSI methods with adjustment for potential confounding factors and clustering in the ED setting.

To address the knowledge gap in the literature, we analyzed data from a multicenter prospective observational study to investigate intubation success and complication 
rates with the use of RSI compared to those of non-RSI methods in the ED.

\section{Methods \\ Study design and setting}

This study was a secondary analysis of the data from the first Japanese Emergency Airway Network (JEAN-1) Study, a multicenter prospective observational study designed to characterize the current ED airway management across Japan. The study setting, methods of measurement, and measured variables are described elsewhere [14-18]. In sum, JEAN-1 is a consortium of 13 academic and community medical centers from different geographic regions across Japan. All 13 EDs were staffed by emergency attending physicians; 12 had affiliations with emergency medicine residency training programs. Emergency attending physicians were defined as postgraduate years 6 or more; emergency medicine resident physicians were defined as postgraduate years 3 , 4, or 5. Participating institutions included level I $(n=11)$ or level II equivalent $(n=2)$ trauma centers with a median ED census of 25,000 patient visits per year (range, 4200-67,000). Each ED maintained individual protocols, policies, and procedures for ED airway management. Intubations were performed by attending physicians or by resident physicians at the discretion of supervising ED attending physicians. The institutional review board of each participating center approved the protocol with waiver of informed consent prior to data collection.

\section{Selection of participants}

All adults and children who underwent emergency intubation during a 29-month period (April 2010 to August 2012) were eligible for inclusion in analyses. As intubations without medications are the widely adopted initial method in patients with cardiac arrest, we excluded this population from the analysis [19]. We also excluded patients who underwent intubation with paralytics alone, flexible fiberoptic intubation, blind nasal intubation, or surgical cricothyrotomy to compare the outcomes between oral intubations with RSI and those with non-RSI. In addition, we excluded patients with multiple intubation attempts using an alternative method (e.g., changes in the intubation method from non-RSI to RSI) from the analysis for the secondary outcome to compare the outcomes between intubations with RSI and those with non-RSI that used the same intubation method both on the first and second attempt (i.e., we excluded patients who underwent the second intubation attempt with different methods).

\section{Methods of measurement}

After each ED intubation, the operator completed a standardized data collection form that included the patient age, sex, primary indication for intubation, method of intubation, all medications used to facilitate intubation, device, specialties and training level of intubator, number of attempts, success or failure, and complications [14-18]. Methods of intubation, medications and dosages, and devices were chosen at the discretion of operators. We monitored compliance with data form completion by reviewing professional billing records. Where the data collection form was missing, we interviewed the involved physicians to ascertain airway management details. These post hoc interviews occurred within 2 weeks of the patient encounters.

\section{Outcome measures}

The primary outcome measure was successful on the first intubation attempt. The secondary outcome measures were successful within the second attempt and intubationassociated complications (overall and major). Intubation success was defined as the proper placement of an endotracheal tube through the vocal cord confirmed by quantitative or colorimetric end-tidal $\mathrm{CO}_{2}$ monitoring [20]. An intubation "attempt" was defined as a single insertion of the laryngoscopy past the teeth [15]. Complications were defined as cardiac arrest, hypotension, hypoxemia, regurgitation, esophageal intubation with delayed recognition, main stem bronchial intubation, dental or lip trauma, airway trauma, or allergic reaction [17]. Cardiac arrest included asystole, pulseless electric activity, or dysrhythmia with nonmeasurable blood pressure [17]. Hypotension was defined as systolic blood pressure less than $90 \mathrm{mmHg}$ [17]. Hypoxemia was defined as pulse oximetry saturation less than $90 \%$ during an intubation attempt, not secondary to esophageal intubation [17]. We also defined major complications as cardiac arrest, hypotension, hypoxemia, regurgitation, or esophageal intubation with delayed recognition [17].

\section{Statistical analysis}

We first analyzed the compiled data with simple descriptive statistics. Continuous data are presented as means and standard deviations (SD); categorical data are reported as proportions. Next, we compared outcomes between RSI and non-RSI methods in ED patients who underwent intubation attempts. RSI was defined as the administration of a potent induction agent followed immediately by a rapidly acting paralytic agent to induce unconsciousness and motor paralysis for intubation $[1,8,15,19,21]$. NonRSI was defined as intubation with sedative agent only or intubation without medications. We fit three unconditional logistic regression models: (1) unadjusted model, (2) adjusted model for selected variables, and (3) adjusted random-effects model for selected variables and potential clustering of patients within EDs, with each of the four outcome measures as dependent variables. Based on $a$ priori knowledge, we chose a set of potential confounders (age, sex, estimated weight, principal indication for intubation, device, and the specialties and training level of intubator) $[3,7,8,13,22]$. In the regression model, the 
predictive effects on outcomes were assessed for RSI with non-RSI as a reference group.

In the sensitivity analyses, first, we repeated the multivariable analysis stratifying the non-RSI methods into intubation with sedative agent only and intubation without medications. Second, we repeated the model in a subgroup of patients at the level I trauma centers. Lastly, we repeated the model excluding intubations with slow-onset medications, such as midazolam, diazepam, haloperidol, and vecuronium from the RSI group. All odds ratios (ORs) were presented with $95 \%$ confidence intervals (CIs). All tests were 2-tailed, and $P<0.05$ was regarded as statistically significant. Data analyses were conducted with JMP statistical software (version 10; SAS Institute, Inc., Cary, $\mathrm{NC}$ ) and R software, version 3.0.2. (www.r-project.org).

\section{Results}

During the 29-month period, there were 4268 patients requiring emergency airway management at the 13 EDs (Fig. 1). Among these, 4094 intubations were recorded in the database (capture rate, 96\%). From this cohort, we excluded 1555 patients with cardiac arrest and 174 patients who underwent an initial intubation attempt with paralytics alone, flexible fiberoptic intubation, blind nasal intubation, cricothyrotomy, or other methods. After these exclusions, we analyzed 2365 patients for the primary outcome. Of these, RSI was used for 761 patients (32\%) and non-RSI was used for 1604 patients (68\%). For the secondary outcomes, we further excluded 48 patients with subsequent intubation attempts using an alternative intubation method: fiberoptic intubation $(n=1)$, RSI $(n=26)$, blind nasal intubation $(n=$ $1)$, cricothyrotomy $(n=4)$, intubation with paralytics alone $(n=4)$, and intubation with sedative agent only $(n=9)$ at the second attempt. After these exclusions, the analytic cohort comprised 2317 ED patients for the secondary outcomes.

\section{Patient and airway management characteristics}

The mean age of patients was 61 years, and the majority was male (Table 1). Most intubations involved medical emergencies. RSI was less commonly used for medical

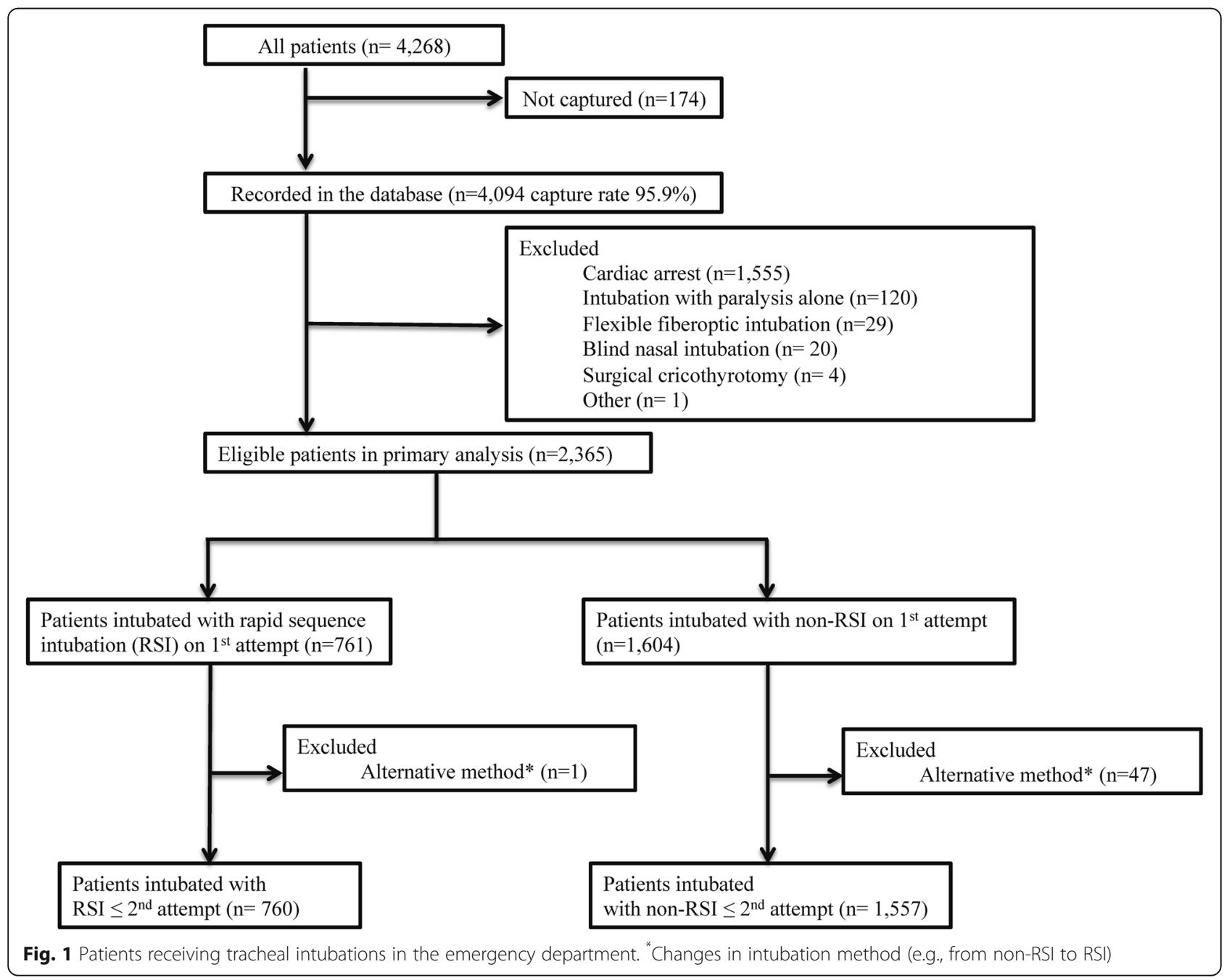


Table 1 Characteristics of 2365 patients receiving intubation in the emergency department ${ }^{\mathrm{a}}$

\begin{tabular}{|c|c|c|}
\hline \multirow[t]{2}{*}{ Patient characteristics } & RSI & Non-RSI \\
\hline & $(n=761)$ & $(n=1604)$ \\
\hline Age, mean (SD), years & $61(20)$ & $61(21)$ \\
\hline Age $\leq 18$ years $(\%)$ & $23(3 \%)$ & $64(4 \%)$ \\
\hline Age <2 years (\%) & $4(0.5 \%)$ & $18(1 \%)$ \\
\hline Age 2-9 years (\%) & $7(0.9 \%)$ & $22(1 \%)$ \\
\hline Age $10-18$ years (\%) & $12(2 \%)$ & $24(1 \%)$ \\
\hline Male sex (\%) & $470(62 \%)$ & 941 (59\%) \\
\hline Body weight, mean (SD), kg & $59(15)$ & $59(17)$ \\
\hline \multicolumn{3}{|l|}{ Primary indication (\%) } \\
\hline Medical encounters & $589(77 \%)$ & $1333(83 \%)$ \\
\hline Respiratory failure & $239(31 \%)$ & $303(19 \%)$ \\
\hline Altered mental status & $231(30 \%)$ & 712 (44\%) \\
\hline Shock & $93(13 \%)$ & $216(13 \%)$ \\
\hline Airway obstruction & $11(1 \%)$ & $78(5 \%)$ \\
\hline Asthma & $7(0.9 \%)$ & $10(0.6 \%)$ \\
\hline Other medical & $8(1 \%)$ & $14(0.8 \%)$ \\
\hline Trauma encounters & $172(23 \%)$ & $271(17 \%)$ \\
\hline Head trauma & $65(9 \%)$ & $138(9 \%)$ \\
\hline Shock & $55(7 \%)$ & $60(4 \%)$ \\
\hline Burn/inhalation & $23(3 \%)$ & $16(1 \%)$ \\
\hline Facial/neck trauma & $15(2 \%)$ & $35(2 \%)$ \\
\hline Other trauma & $14(2 \%)$ & $22(1 \%)$ \\
\hline
\end{tabular}

Abbreviation: $R S /$ rapid sequence intubation, $S D$ standard deviation

apercentage may not equal 100 because of rounding

encounters (77\%) compared to non-RSI methods (83\%). By contrast, RSI was more commonly used for trauma encounters (23\%) than non-RSI (17\%).

The most frequently used sedative agent was midazolam in the RSI group and propofol in the non-RSI group (Table 2). The most common paralytic agent used in RSI was rocuronium. Among the patients intubated with non-RSI methods, intubation with sedative agent only was used in 54\% and intubation without medications in $45 \%$. Direct laryngoscopy was used $98 \%$ in the RSI group and $96 \%$ in the non-RSI group.

\section{Intubation successes and complications}

In the unadjusted analysis (Table 3), intubations with RSI method had a higher chance of success both on the first attempt (73\% [95\% CI, 69-76\%] vs. 63\% [95\% CI, 60-65\%]; unadjusted OR 1.6; 95\% CI, 1.3-1.9; $P<0.0001$ ) and within the second attempt (90\% [95\% CI, 88-92\%] vs. 87\% [95\% CI, 85-88\%]; unadjusted OR 1.5; 95\% CI, 1.11.9; $P<0.01)$ compared to those with non-RSI methods. Likewise, intubation with RSI was independently associated with a higher chance of intubation success both on the first attempt (OR 2.1; 95\% CI, 1.7-2.6; $P<0.0001)$ and
Table 2 Airway management characteristics in 2365 patients receiving intubation in the emergency department ${ }^{a}$

\begin{tabular}{|c|c|c|}
\hline & $\begin{array}{l}\text { RSI } \\
(n=761)\end{array}$ & $\begin{array}{l}\text { Non-RSI } \\
(n=1604)\end{array}$ \\
\hline \multicolumn{3}{|l|}{ Initial method (\%) } \\
\hline Rapid sequence intubation (RSI) & $761(100 \%)$ & 0 \\
\hline Intubation with sedative agent only & 0 & $871(54 \%)$ \\
\hline Intubation without medications & 0 & $729(45 \%)$ \\
\hline Other ${ }^{b}$ & 0 & $4(0.2 \%)$ \\
\hline \multicolumn{3}{|l|}{ Sedatives (\%) } \\
\hline No sedatives & 0 & $733(46 \%)$ \\
\hline Midazolam & $427(56 \%)$ & $255(16 \%)$ \\
\hline Dosage, mean (SD), mg/kg & $0.09(0.07)$ & $0.1(0.07)$ \\
\hline Diazepam & $104(14 \%)$ & $71(4 \%)$ \\
\hline Dosage, mean (SD), mg/kg & $0.2(0.19)$ & $0.2(0.08)$ \\
\hline Propofol & $103(14 \%)$ & $406(25 \%)$ \\
\hline Dosage, mean (SD), mg/kg & $1.3(0.8)$ & $1.1(0.6)$ \\
\hline Ketamine & $87(11 \%)$ & $37(2 \%)$ \\
\hline Dosage, mean (SD), mg/kg & $1.0(0.3)$ & $1.0(0.6)$ \\
\hline $\begin{array}{l}\text { Combination with any of the } \\
\text { included sedative categories }\end{array}$ & $7(0.9 \%)$ & $18(1 \%)$ \\
\hline Other ${ }^{c}$ & $33(4 \%)$ & $84(5 \%)$ \\
\hline \multicolumn{3}{|l|}{ Paralytics (\%) } \\
\hline No paralytic & 0 & $1604(100 \%)$ \\
\hline Rocuronium & $531(70 \%)$ & 0 \\
\hline Dosage, mean (SD), mg/kg & $0.9(0.3)$ & \\
\hline Vecuronium & $161(21 \%)$ & 0 \\
\hline Dosage, mean (SD), mg/kg & $0.1(0.04)$ & \\
\hline Succinylcholine & $69(9 \%)$ & 0 \\
\hline Dosage, mean (SD), mg/kg & $1.1(0.4)$ & \\
\hline
\end{tabular}

Device (\%)

\begin{tabular}{lll} 
Direct laryngoscopy & $746(98 \%)$ & $1545(96 \%)$ \\
Direct laryngoscopy + gum elastic bougie & $2(0.2 \%)$ & $7(0.4 \%)$ \\
Video laryngoscopy & $13(2 \%)$ & $50(3 \%)$ \\
Video laryngoscopy + gum elastic bougie & 0 & $1(0.06 \%)$ \\
Lighted stylet $^{\text {Specialty of first intubator (\%) }}$ & 0 & $1(0.06 \%)$ \\
Transitional year resident $^{d}$ & $321(42 \%)$ & $462(29 \%)$ \\
Emergency medicine resident $_{\text {Emergency physician }}$ & $141(19 \%)$ & $679(42 \%)$ \\
Other specialty & $177(23 \%)$ & $305(19 \%)$ \\
Unknown & $122(16 \%)$ & $156(10 \%)$ \\
\hline
\end{tabular}

Abbreviation: $R S /$ rapid sequence intubation, $S D$ standard deviation aPercentage may not equal 100 because of rounding

${ }^{\mathrm{b}}$ Defined as oral intubation using topical anesthesia, lidocaine, or atropine 'Defined as administration of fentanyl, morphine, buprenorphine, pentazocine, or haloperidol

${ }^{\mathrm{d}}$ Defined as post graduate years 1 or 2

${ }^{e}$ Defined as internal medicine, surgery, anesthesia, or pediatrics 
Table 3 Unadjusted associations of intubation method with intubation outcomes

\begin{tabular}{|c|c|c|c|c|}
\hline$n(\%, 95 \% C l)$ & Success on 1st attempt & Success $\leq 2$ nd attempt & Complication $^{\mathrm{a}}$ & Major complication ${ }^{\mathrm{b}}$ \\
\hline \multicolumn{5}{|l|}{ RSI } \\
\hline $\begin{array}{l}\text { ( } n=761 \text { on } 1 \text { st attempt } \\
n=760 \leq 2 \text { nd attempt) }\end{array}$ & $\begin{array}{l}553 \\
(73 \%, 69-76 \%)\end{array}$ & $\begin{array}{l}687 \\
(90 \%, 88-92 \%)\end{array}$ & $\begin{array}{l}93 \\
(12 \%, 10-15 \%)\end{array}$ & $\begin{array}{l}62 \\
(8 \%, 6-10 \%)\end{array}$ \\
\hline \multicolumn{5}{|l|}{ Non-RSI } \\
\hline $\begin{array}{l}\text { ( } n=1604 \text { on } 1 \text { st attempt } \\
n=1557 \leq 2 \text { d attempt })\end{array}$ & $\begin{array}{l}1003 \\
(63 \%, 60-65 \%)\end{array}$ & $\begin{array}{l}1348 \\
(87 \%, 85-88 \%)\end{array}$ & $\begin{array}{l}209 \\
(13 \%, 11-15 \%)\end{array}$ & $\begin{array}{l}122 \\
(8 \%, 6-9 \%)\end{array}$ \\
\hline \multicolumn{5}{|c|}{ Intubation with sedative agent only } \\
\hline $\begin{array}{l}\text { ( } n=871 \text { on } 1 \text { st attempt } \\
n=849 \leq 2 \text { d attempt })\end{array}$ & $\begin{array}{l}542 \\
(62 \%, 59-65 \%)\end{array}$ & $\begin{array}{l}724 \\
(85 \%, 83-88 \%)\end{array}$ & $\begin{array}{l}121 \\
(14 \%, 12-16 \%)\end{array}$ & $\begin{array}{l}72 \\
(8 \%, 7-10 \%)\end{array}$ \\
\hline \multicolumn{5}{|c|}{ Intubation without medications } \\
\hline $\begin{array}{l}\text { ( } n=729 \text { on } 1 \text { st attempt } \\
n=706 \leq 2 \text { nd attempt) }\end{array}$ & $\begin{array}{l}460 \\
(63 \%, 60-66 \%)\end{array}$ & $\begin{array}{l}622 \\
(88 \%, 86-90 \%)\end{array}$ & $\begin{array}{l}86 \\
(12 \%, 10-14 \%)\end{array}$ & $\begin{array}{l}50 \\
(7 \%, 5-9 \%)\end{array}$ \\
\hline
\end{tabular}

Abbreviation: $R S I$ rapid sequence intubation, $\mathrm{Cl}$ confidence interval

aDefined as cardiac arrest, hypotension, hypoxemia, regurgitation, esophageal intubation with delayed recognition, main stem bronchial intubation, dental or lip trauma, airway trauma, or allergic reaction

befined as cardiac arrest, hypotension, hypoxemia, regurgitation, or esophageal intubation with delayed recognition

within the second attempt (OR 1.8; 95\% CI, 1.4-2.6; $P<$ 0.0001 ) after adjusting for potential confounders (Table 4; Appendix 1: Table 5). The adjusted association persisted with the use of random-effects model accounting for clustering within the EDs, in the subgroup analysis of patients in the level-I trauma centers (Appendix 2: Table 6), with stratification by non-RSI method (Table 4), and with stratification by RSI method (Appendix 3: Table 7).

By contrast, between the RSI and non-RSI methods, there was no significant difference in the unadjusted complication rate $(12 \%$ [95\% CI, $10-15 \%]$ vs. $13 \%$ [95\% CI, $11-15 \%]$; unadjusted OR $0.9 ; 95 \% \mathrm{CI}, 0.7-1.2 ; P=0.58)$ or in the major complication rate $(8 \%$ [95\% CI, $6-10 \%]$ vs. $8 \%$ [95\% CI, 6-9\%]; unadjusted OR 1.1; 95\% CI, 0.8-1.5; $P=0.65$; Table 3; Appendix 4: Table 8). The multivariable adjusted models and stratified analysis confirmed these null findings in the complication rates (Table 4; Appendix 1: Table 5).

\section{Discussion}

In this large prospective study of 2365 ED patients who underwent intubation attempts in the ED, we found that intubation attempt using RSI was associated with a higher chance of success both on the first attempt and within second attempt, compared to that using non-RSI. These significant associations persisted across various statistical assumptions. By contrast, we also found no significant differences in the risk of intubation-related complication between the two intubation methods.

Several previous studies have reported a high-success intubation rate and low complication rate with the use of RSI [4, 7-13]. For example, in the descriptive analysis of a prospective observational study (the National Emergency Airway Registry (NEAR)) of airway management in North American EDs [8], Walls et al. reported that RSI was the most frequently used initial method chosen (69\%) and that

Table 4 Multivariable associations of intubation methods with intubation outcomes

\begin{tabular}{|c|c|c|c|c|}
\hline & $\begin{array}{l}\text { Success on 1st attempt, } \\
\text { adjusted OR }(95 \% \mathrm{Cl}) \\
P \text { value }\end{array}$ & $\begin{array}{l}\text { Success } \leq 2 \text { nd attempt, } \\
\text { adjusted OR (95\% Cl) } \\
P \text { value }\end{array}$ & $\begin{array}{l}\text { Complications }{ }^{c}, \\
\text { adjusted OR }(95 \% \mathrm{Cl}) \\
P \text { value }\end{array}$ & $\begin{array}{l}\text { Major complications }{ }^{d}, \\
\text { adjusted OR (95\% Cl) } \\
P \text { value }\end{array}$ \\
\hline \multicolumn{5}{|l|}{ RSI versus non-RSI } \\
\hline Multivariable model adjusting for selected variables ${ }^{a}$ & $2.1(1.7-2.6) P<0.0001$ & $1.8(1.4-2.6) P<0.0001$ & $1.0(0.7-1.3) P=0.76$ & $1.0(0.7-1.5) P=0.76$ \\
\hline $\begin{array}{l}\text { Multivariable model adjusting for selected variables } \\
\text { and clustering of patients }{ }^{b}\end{array}$ & $2.3(1.8-2.9) P<0.0001$ & $1.9(1.1-3.0) P<0.0001$ & $0.9(0.6-1.2) P=0.31$ & $0.9(0.6-1.3) P=0.53$ \\
\hline \multicolumn{5}{|c|}{ Stratified analysis by non-RSI methods adjusting for selected variables ${ }^{a}$} \\
\hline RSI vs. intubation with sedative agent only & $2.2(1.7-2.8) P<0.0001$ & $2.2(1.6-3.0) P<0.0001$ & $0.8(0.6-1.2) P=0.30$ & $0.9(0.6-1.3) P=0.63$ \\
\hline RSI vs. intubation without medications & $2.0(1.6-2.6) P<0.0001$ & $1.5(1.0-2.1) P=0.03$ & $1.1(0.8-1.5) P=0.54$ & $1.2(0.8-1.9) P=0.35$ \\
\hline \multicolumn{5}{|c|}{ 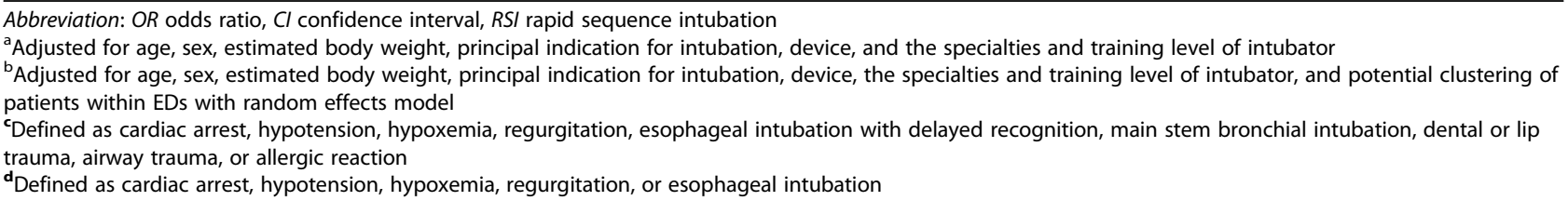 } \\
\hline
\end{tabular}


the unadjusted success rate of RSI on the first attempt was higher than that of intubations with sedation without paralytics (82 vs. 76\%). They also found that the unadjusted complication rate in patients intubated with RSI was lower than that with sedation without paralytics (11 vs. $16 \%$ ). Similarly, in a prospective observational study of 1478 intubations at two academic EDs in Korea, Kim et al. reported that RSI was associated with a higher success rate on the first attempt [13]. Our data corroborate these findings and expand these prior researches by using more robust statistical approach in a different patient population and practice setting. Along with the existing literature, our findings lend significant support to the current ED management-RSI as the method of choice.

There are several plausible mechanisms of the observed higher success with the use of RSI than with non-RSI methods. The literature in the operating room setting demonstrated that intubations with RSI lead to better intubating conditions such as abducted vocal cords, lack of vocal cord movement, ease of laryngoscopy, and lack of cough reflex when compared to those with sedatives only $[9,10]$. Alternatively, patient selections by indication-e.g., patients who underwent intubation with RSI were less likely to have had predicted difficult laryngoscopy-may have contributed to the higher success rate with the use of RSI. Indeed, the guidelines and experts recommend that the RSI methods should be avoided for patients with predicted difficult laryngoscopy [23].

We found no significant difference in the complication rate between the RSI and non-RSI groups, although the previous studies reported that intubations with RSI had a lower rate of complications $[8,12]$. The reasons of this discrepancies are likely multifactorial-e.g., differences in study design, setting, data measurement, definition of outcomes, or any combination of these factors. Alternatively, it is possible that, in our study population, non-RSI methods were used more frequently and potentially less selectively (i.e., non-RSI methods were also used for patients with less-difficult airway), which may have resulted in a relatively lower rate of complications in the non-RSI group, compared with previous studies, thereby leading to the null results $[5,7,8]$.

We are struck with the discrepancies not only in the use of RSI but also in the success rates between our study and previous studies. For example, Walls et al. reported the first-pass success rates using RSI of $82 \%$ and intubation with sedation only of $76 \%$ [8] while the rates in our study were 73 and $63 \%$, respectively. The reasons of those discrepancies are likely multifactorial, such as the wide inter-hospital variation in emergency airway management, lack of standard education of emergency airway management, lack of accreditation of emergency medicine training program in Japan, or any combination of these factors $[15,24]$.

\section{Potential limitations}

Our study has several potential limitations. First, surveillance systems used in this study are subject to selfreporting bias, thereby leading overestimation of success rate and underestimation of complication rates. However, these non-differential misclassifications may not have biased our inferences as over and under estimations could evenly occur in the both groups. Second, this registry was not designed to assess patient outcomes after ED disposition such as in-hospital mortality. Third, the dosage of rocuronium, the most commonly used paralytics in this registry, was lower $(0.9 \mathrm{mg} / \mathrm{kg})$ than the standard dosage in RSI $(1.0 \mathrm{mg} / \mathrm{kg})$ [19]. However, the finding that intubation using RSI even with suboptimal dosage of paralytics demonstrated a higher success rate than that using non-RSI supports the favorable effectiveness of RSI. Fourth, some factors of airway management (e.g., preoxygenation, cricoid pressure, predicted airway difficulty, peri-intubation vital signs, rationale of medication dosage, and time-related factors such as duration between medication administration to intubation) were not assessed in this registry. Fifth, as with any observational study, the association between RSI method and a higher chance of intubation success does not necessarily prove causality and may be confounded by unmeasured factors, such as patient's underlying comorbidity, airway difficulty, and differences in procedural skill. High-quality clinical trials of ED airway management would be instrumental in demonstrating causality between airway management methods and outcomes. However, such trials are ethically difficult given the existing literature showing a superiority of the RSI compared to the non-RSI techniques in the ED setting. Additionally, it is well documented that patients who consent to participate in the controlled framework of a clinical trial may be systematically different from the general population [25]. As an alternative, our large prospective multicenter data in the "real world" setting reflect the effectiveness of ED airway management, therefore enhancing the potential generalizability of the findings.

\section{Conclusions}

In conclusion, in this large multicenter prospective observational study in Japanese EDs, intubations with RSI had a higher chance of intubation success both on the first and within second attempt but no significant difference in the risk of complication when compared to the non-RSI methods. For clinicians, these findings lend significant support to the use of RSI in the ED by providing more robust evidence of its superior effectiveness in emergency airway management. For researchers, because the evidence for accurately predicting patients in whom RSI should be avoided remains to be elucidated, our data should facilitate further investigation on risk stratification of patients who require airway management in the ED. 


\section{Appendix 1}

Table 5 Multivariable model of rapid sequence intubation versus non-rapid sequence intubation

\begin{tabular}{|c|c|c|c|c|}
\hline & $\begin{array}{l}\text { Success } \\
\text { on 1st } \\
\text { attempt }\end{array}$ & $\begin{array}{l}\text { Success } \leq 2 \mathrm{nd} \\
\text { attempt, } \\
\text { adjusted } \\
\text { OR (95\% Cl) }\end{array}$ & $\begin{array}{l}\text { Complication }{ }^{a} \text {, } \\
\text { adjusted OR } \\
(95 \% \text { Cl) }\end{array}$ & $\begin{array}{l}\text { Major } \\
\text { complication } \\
\text { adjusted } \\
\text { OR }(95 \% \text { Cl) }\end{array}$ \\
\hline \multicolumn{5}{|c|}{ Primary exposure } \\
\hline $\begin{array}{l}\text { RSI } \\
\text { (vs. non-RSI) }\end{array}$ & $2.1(1.7-2.6)$ & $1.8(1.4-2.6)$ & $1.0(0.7-1.3)$ & $1.0(0.7-1.5)$ \\
\hline \multicolumn{5}{|l|}{ Covariates } \\
\hline Age decile & $1.0(1.0-1.0)$ & $1.0(1.0-1.0)$ & $1.0(1.0-1.0)$ & $1.0(1.0-1.0)$ \\
\hline $\begin{array}{l}\text { Male } \\
\text { (vs. female) }\end{array}$ & $0.8(0.7-1.0)$ & $0.8(0.6-1.1)$ & $0.8(0.6-1.0)$ & $0.9(0.6-1.3)$ \\
\hline $\begin{array}{l}\text { Estimated } \\
\text { body weight } \\
\text { decile }\end{array}$ & $1.0(1.0-1.0)$ & $1.0(1.0-1.0)$ & $1.0(1.0-1.0)$ & $1.0(1.0-1.0)$ \\
\hline \multicolumn{5}{|c|}{ Primary indication } \\
\hline $\begin{array}{l}\text { Medical } \\
\text { indication }^{c}\end{array}$ & 1 [reference] & 1 [reference] & 1 [reference] & 1 [reference] \\
\hline Trauma $^{d}$ & $0.6(0.5-0.7)$ & $0.7(0.5-1.0)$ & $1.1(0.7-1.3)$ & $0.9(0.6-1.5)$ \\
\hline \multicolumn{5}{|l|}{ Device } \\
\hline $\begin{array}{l}\text { Direct } \\
\text { laryngoscopy }\end{array}$ & 1 [reference] & 1 [reference] & 1 [reference] & 1 [reference] \\
\hline $\begin{array}{l}\text { Video } \\
\text { laryngoscopy }\end{array}$ & $0.6(0.3-1.0)$ & $0.4(0.2-0.8)$ & $1.5(0.7-2.7)$ & $0.9(0.3-2.2)$ \\
\hline Other ${ }^{\mathrm{e}}$ & $1.0(0.3-3.7)$ & $0.2(0.1-0.5)$ & $1.4(0.5-3.5)$ & $0.9(0.1-3.2)$ \\
\hline \multicolumn{5}{|l|}{ Intubator } \\
\hline $\begin{array}{l}\text { Emergency } \\
\text { physician }\end{array}$ & 1 [reference] & 1 [reference] & 1 [reference] & 1 [reference] \\
\hline $\begin{array}{l}\text { Transitional- } \\
\text { year resident }{ }^{f}\end{array}$ & $0.2(0.2-0.3)$ & $0.2(0.1-0.3)$ & $1.2(0.9-1.8)$ & $1.0(0.6-1.6)$ \\
\hline $\begin{array}{l}\text { Emergency } \\
\text { medicine } \\
\text { resident }\end{array}$ & $0.7(0.5-0.9)$ & $0.8(0.5-1.1)$ & $1.1(0.8-1.5)$ & $0.6(0.4-1.0)$ \\
\hline Other $^{g}$ & $0.4(0.3-0.5)$ & $0.4(0.3-0.7)$ & $1.3(0.9-2.1)$ & $1.8(1.1-3.0)$ \\
\hline
\end{tabular}

Abbreviation: $O R$ odds ratio, $\mathrm{Cl}$ confidential interval, $R S /$ rapid sequence intubation

${ }^{a}$ Defined as cardiac arrest, hypotension, hypoxemia, regurgitation, esophageal intubation with delayed recognition, main stem bronchial intubation, dental or lip trauma, airway trauma, or allergic reaction

befined as cardiac arrest, hypotension, hypoxemia, regurgitation, or esophageal intubation

'Defined as altered mental status, respiratory failure, shock, airway obstruction, asthma, or other medical indications

dDefined as head trauma, shock, facial/neck trauma, burn/inhalation, or other trauma indications

${ }^{\mathrm{e}}$ Defined as direct laryngoscopy or video laryngoscopy with gum elastic

bougie or lighted stylet

fDefined as postgraduate years 1 or 2

${ }^{9}$ Defined as surgery, anesthesia, or pediatrics

\section{Appendix 2}

Table 6 Random-effects model of rapid sequence intubation versus non-rapid sequence intubation in all patients and patients at level I trauma centers

Success on 1st attempt Success on 1st attempt (all patients $[n=2365]), \quad$ (patients at level I trauma Adjusted OR $(95 \% \mathrm{Cl}) \quad$ centers $[n=2147])$ Adjusted OR $(95 \% \mathrm{Cl})$

Primary exposure

RSI (vs, non-RSI)

$2.3(1.8-2.9)$

$2.0(1.6-2.6)$

Covariates

Age decile

$1.0(1.0-1.0)$

$1.0(1.0-1.0)$

Male (vs. female)

$0.8(0.7-1.0)$

$0.8(0.6-0.9)$

Estimated body

$1.0(1.0-1.0)$

$1.0(1.0-1.0)$

weight decile

Primary indication

Medical indication ${ }^{\mathrm{a}} \quad 1$ [reference] 1 [reference]

$\begin{array}{lll}\text { Trauma }^{\mathrm{b}} & 0.6(0.5-0.8) & 0.6(0.5-0.8)\end{array}$

Device

Direct laryngoscopy 1 [reference] 1 [reference]

Video laryngoscopy $0.6(0.4-1.1) \quad 0.7(0.3-1.6)$

Other $^{\mathrm{c}}$

$0.9(0.3-3.4)$

$0.9(0.2-3.3)$

Intubator

Emergency

physician

Transitional-year

resident $^{\mathrm{d}}$

$\begin{array}{lll}\text { Emergency } & 0.5(0.4-0.7) & 0.6(0.4-0.8)\end{array}$

medicine resident

Other $^{\mathrm{e}}$

$0.3(0.2-0.5)$

$0.4(0.3-0.6)$

${ }^{a}$ Defined as altered mental status, respiratory failure, shock, airway obstruction, asthma, or other medical indications

${ }^{b}$ Defined as head trauma, shock, facial/neck trauma, burn/inhalation, or other trauma indications

'Defined as direct laryngoscopy or video laryngoscopy with gum elastic bougie or lighted stylet

${ }^{\mathrm{d} D e f i n e d}$ as postgraduate years 1 or 2

'Defined as surgery, anesthesia, or pediatrics 


\section{Appendix 3}

Table 7 Multivariable association of stratified RSI with intubation outcomes ${ }^{\mathrm{a}}$

\begin{tabular}{|c|c|c|c|c|}
\hline & $\begin{array}{l}\text { Success on 1st attempt, } \\
\text { Adjusted OR }(95 \% \mathrm{Cl}) \\
P \text { value }\end{array}$ & $\begin{array}{l}\text { Success } \leq 2 \text { nd attempt, } \\
\text { Adjusted OR }(95 \% \mathrm{Cl}) \\
P \text { value }\end{array}$ & $\begin{array}{l}\text { Complications }{ }^{c} \text {, } \\
\text { Adjusted OR } \\
(95 \% \text { Cl) } P \text { value }\end{array}$ & $\begin{array}{l}\text { Major complications }{ }^{\text {d }} \text {, } \\
\text { Adjusted OR }(95 \% \mathrm{Cl}) \\
P \text { value }\end{array}$ \\
\hline Modified RSI ${ }^{b}$ vs. non-RSI & $\begin{array}{l}2.2 \\
(1.5-3.2) \\
P=0.0012\end{array}$ & $\begin{array}{l}1.4 \\
(0.9-2.4) \\
P=0.15\end{array}$ & $\begin{array}{l}0.7 \\
(0.4-1.2) \\
P=0.19\end{array}$ & $\begin{array}{l}0.6 \\
(0.3-1.2) \\
P=0.16\end{array}$ \\
\hline Modified RSI ${ }^{b}$ vs. intubation with sedative agent only & $\begin{array}{l}2.4 \\
(1.6-3.6) \\
P<0.0001\end{array}$ & $\begin{array}{l}1.7 \\
(1.0-2.9) \\
P=0.05\end{array}$ & $\begin{array}{l}0.6 \\
(0.4-1.1) \\
P=0.11\end{array}$ & $\begin{array}{l}0.5 \\
(0.2-1.0) \\
P=0.07\end{array}$ \\
\hline Modified RSI ${ }^{b}$ vs. intubation without medications & $\begin{array}{l}1.9 \\
(1.3-3.0) \\
P=0.0006\end{array}$ & $\begin{array}{l}1.1 \\
(0.7-2.0) \\
P=0.64\end{array}$ & $\begin{array}{l}0.9 \\
(0.5-1.5) \\
P=0.55\end{array}$ & $\begin{array}{l}0.8 \\
(0.3-1.6) \\
P=0.53\end{array}$ \\
\hline
\end{tabular}

Abbreviation: $O R$ odds ratio, $C l$ confidence interval, $R S I$ rapid sequence intubation

${ }^{a}$ Adjusted for age, sex, estimated body weight, principal indication for intubation, device, and the specialties and training level of intubator

${ }^{b}$ Excluded cases that used vecuronium, midazolam, diazepam, and haloperidol

'Defined as cardiac arrest, hypotension, hypoxemia, regurgitation, esophageal intubation with delayed recognition, main stem bronchial intubation, dental or lip

trauma, airway trauma, or allergic reaction

${ }^{\mathrm{d} D e f i n e d}$ as cardiac arrest, hypotension, hypoxemia, regurgitation, or esophageal intubation with delayed recognition

\section{Appendix 4}

Table 8 Complications in 2317 patients receiving intubation in the emergency department ${ }^{a}$

\begin{tabular}{|c|c|c|c|c|}
\hline Complications (\%) & $\operatorname{RSI}(n=760)$ & Non-RSI $(n=1557)$ & $\begin{array}{l}\text { Intubation with sedative } \\
\text { agent only }(n=849)\end{array}$ & $\begin{array}{l}\text { Intubation without } \\
\text { medications }(n=706 \text { ) }\end{array}$ \\
\hline Cardiac arrest & $5(<1)$ & $3(<1)$ & $1(<1)$ & $2(<1)$ \\
\hline Hypotension & $26(3)$ & $25(2)$ & $24(3)$ & $1(<1)$ \\
\hline Hypoxemia & $1(<1)$ & $5(<1)$ & $2(<1)$ & $3(<1)$ \\
\hline Regurgitation & $8(1)$ & $30(2)$ & $14(2)$ & $16(2)$ \\
\hline Esophageal intubation with delayed recognition & $27(4)$ & $74(5)$ & $40(5)$ & $34(5)$ \\
\hline Main stem bronchial intubation & $14(2)$ & $20(1)$ & $7(<1)$ & $13(2)$ \\
\hline Dental or lip trauma & $13(2)$ & $70(4)$ & $43(5)$ & $27(4)$ \\
\hline Airway trauma & $3(<1)$ & $5(<1)$ & $1(<1)$ & $4(<1)$ \\
\hline Allergic reaction & $1(<1)$ & $0(0)$ & $0(0)$ & $0(0)$ \\
\hline
\end{tabular}

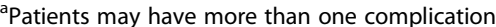

\section{Abbreviations}

Cl: Confidence interval; ED: Emergency department; JEAN: Japanese emergency airway network; NEAR: National emergency airway registry; OR: Odds ratio; RSI: Rapid sequence intubation; SD: Standard deviation

\section{Acknowledgements}

The authors acknowledge the following research personnel at the study hospitals for their assistance with this project: Fukui University Hospital (Hiroshi Morita, MD), Fukui Prefectural Hospital (Hideya Nagai, MD), Japanese Red Cross Medical Centre of Wakayama (Hiroshi Okamoto, MD), Kameda Medical Centre (Kenzo Tanaka, MD, MPH), National Centre for Global Health and Medicine (Shunichiro Nakao, MD), Nagoya Ekisaikai Hospital (Yukari Goto, MD), Nigata City General Hospital (Nobuhiro Sato, MD, MPH), Obama Municipal Hospital (Takuyo Chiba, MD), Okinawa Prefectural Chubu Hospital (Naoki Yamada, MD), Osaka Saiseikai Senri Hospital (Kazuaki Shigemitsu, MD), Shonan Kamakura General Hospital (Taichi Imamura, MD), Kurashiki Central Hospital (Hiroshi Okamoto, MD), and St. Marianna University School of Medicine Hospital (Yasuaki Koyama, MD). Finally, we are grateful to our many emergency physicians for their perseverance in pursuing new knowledge about this vital resuscitative procedure.

\section{Funding}

This study was supported by a grant from St. Luke's Life Science Institute and a grant from Harvard Affiliated Emergency Medicine Residency (PI, Hasegawa). The sponsors of this study have no involvement in the study design, in the collection, analysis, and interpretation of data, in the writing of the manuscript, and in the decision to submit the manuscript for publication.

\section{Authors' contribution}

$\mathrm{MO}, \mathrm{YN}$, and $\mathrm{KH}$ conceived the study. $\mathrm{KH}$ obtained research funding. $\mathrm{KH}$ supervised the conduct of the study and data collection. $\mathrm{KG}$ and $\mathrm{YH}$ managed the data, including quality control. KG, YH, and $\mathrm{KH}$ provided statistical advice on study design and analyzed the data. MO drafted the manuscript and all authors contributed substantially to its revision. MO takes responsibility for the paper as a whole. All authors read and approved the final manuscript. 


\section{Competing interests}

The authors declare that they have no competing interests.

\section{Author details}

'Department of Emergency Medicine, University of Pittsburgh, Iroquois Building Suite 400 A, 3600 Forbes Avenue, Pittsburgh, PA 15261, USA. ${ }^{2}$ Biostatistics Center, Kurume University, 67 Asahimachi, Kurume, Fukuoka 830-0011, Japan. ${ }^{3}$ Department of Pediatric Emergency and Critical Care Medicine, Tokyo Metropolitan Children's Medical Center, 2-8-29 Musashidai, Fuchu, Tokyo 183-8561, Japan. ${ }^{4}$ Department of Emergency Medicine, Okinawa Prefectural Chubu Hospital, 281 Miyazato, Uruma, Okinawa 904-2293, Japan. ${ }^{5}$ Department of Emergency Medicine, Massachusetts General Hospital, 55 Fruit Street, Boston, MA 02114, USA.

Received: 23 November 2015 Accepted: 18 January 2017

Published online: 25 January 2017

\section{References}

1. Brown 3rd CA, Bair AE, Pallin DJ, Walls RM. Techniques, success, and adverse events of emergency department adult intubations. Ann Emerg Med. 2014; 65(4):363-70.

2. Kim JH, Kim YM, Choi HJ, Je SM, Kim E. Factors associated with successful second and third intubation attempts in the ED. Am J Emerg Med. 2013; 31(9):1376-81.

3. Sagarin MJ, Barton ED, Chng Y-M, Walls RM. Airway management by US and Canadian emergency medicine residents: a multicenter analysis of more than 6,000 endotracheal intubation attempts. Ann Emerg Med. 2005;46(4):328-36.

4. Sagarin MJ, Chiang V, Sakles JC, Barton ED, Wolfe RE, Vissers RJ, et al. Rapid sequence intubation for pediatric airway management. Pediatr Emerg Care. 2002;18:417-23.

5. Sakles JC, Laurin EG, Rantapaa AA, Panacek EA. Airway management in the emergency department: a one-year study of 610 tracheal intubations. Ann Emerg Med. 1998;31(3):325-32.

6. Simpson J, Munro PT, Graham CA. Rapid sequence intubation in the emergency department: 5 year trends. Emerg Med J. 2006;23(1):54-6.

7. Tayal VS, Riggs RW, Marx JA, Tomaszewski CA, Schneider RE. Rapidsequence intubation at an emergency medicine residency: Success rate and adverse events during a two-year period. Acad Emerg Med. 1999;6:31-7.

8. Walls RM, Brown 3rd CA, Bair AE, Pallin DJ. Emergency airway management: a multi-center report of 8937 emergency department intubations. J Emerg Med. 2011;41(4):347-54.

9. Naguib M, Samarkandi A, Riad W, Alharby S. Optimal dose of succinylcholine revisited. Anesthesiology. 2003;99:1045-9.

10. Kirkegaard-Nielsen H, Caldwell JE, Berry PD. Rapid tracheal intubation with rocuroniurn. Anesthesiology. 1999;91:131-6.

11. Bozeman WP, Kleiner DM, Huggett V. A comparison of rapid-sequence intubation and etomidate-only intubation in the prehospital air medical setting. Prehosp Emerg Care. 2006;10(1):8-13.

12. Li J, Murphy-Lavoie H, Bugas C, Martinez J, Preston C. Complications of emergency intubation with and without paralysis. Am J Emerg Med. 1999; 17:141-3.

13. Kim C, Kang HG, Lim TH, Choi BY, Shin YJ, Choi HJ. What factors affect the success rate of the first attempt at endotracheal intubation in emergency departments? Emerg Med J. 2013;30(11):888-92.

14. Goto $T$, Watase $H$, Morita $H$, Nagai H, Brown 3rd CA, Brown DF, et al. Repeated attempts at tracheal intubation by a single intubator associated with decreased success rates in emergency departments: an analysis of a multicentre prospective observational study. Emerg Med J. 2015;32(10):781-6.

15. Hasegawa K, Hagiwara Y, Chiba T, Watase H, Walls RM, Brown DF, et al. Emergency airway management in Japan: interim analysis of a multi-center prospective observational study. Resuscitation. 2012:83(4):428-33.

16. Hasegawa K, Hagiwara Y, Imamura T, Chiba T, Watase H, Brown CA, et al. Increased incidence of hypotension in elderly patients who underwent emergency airway management an analysis of a multi-centre prospective observational study. Int J Emeg Med. 2013;6:12.

17. Hasegawa K, Shigemitsu K, Hagiwara Y, Chiba T, Watase H, Brown 3rd CA, et al. Association between repeated intubation attempts and adverse events in emergency departments: an analysis of a multicenter prospective observational study. Ann Emerg Med. 2012;60(6):749-54.

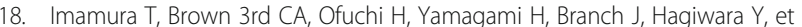
al. Emergency airway management in geriatric and younger patients: analysis of a multicenter prospective observational study. Am J Emerg Med. 2013;31(1):190-6.

19. Walls R, Murphy M. Manual of emergency airway management 4th edition. Philadelphia: Lippincott Williams \& Wilkins, a Wolters Kluwer business; 2012.

20. Neumar RW, Otto CW, Link MS, Kronick SL, Shuster M, Callaway CW, et al. Part 8: adult advanced cardiovascular life support: 2010 American Heart Association Guidelines for Cardiopulmonary Resuscitation and Emergency Cardiovascular Care. Circulation. 2010;122(18 Suppl 3):S729-67.

21. Reynolds SF, Heffner J. Airway management of the critically ill patient. Chest. 2005;127:1397-412.

22. Turkan S, Ates Y, Cuhruk H, Tekdemir I. Should we reevaluate the variables for predicting the difficult airway in anesthesiology? Anesth Analg. 2002;94: $1340-4$.

23. Apfelbaum JL, Hagberg CA, Caplan RA, Blit CD. Practice guidelines for management of the difficult airway: an updated report by the American Society of Anesthesiologists Task Force on Management of the Difficult Airway. Anesthesiology. 2013;118(2):251-70.

24. Yamashita M, Akashi K, Ohta B. Implementation of US-style emergency medicine in accredited training program institutions for fellowship of the Japanese Association for Acute Medicine. J Jpn Assoc Acute Med. 2008;19: 416-23.

25. Black N. Why we need observation studies to evaluate the effectiveness of health care. BMJ. 1996;312:1215-18.

\section{Submit your manuscript to a SpringerOpen ${ }^{\circ}$ journal and benefit from:}

- Convenient online submission

- Rigorous peer review

- Immediate publication on acceptance

- Open access: articles freely available online

- High visibility within the field

- Retaining the copyright to your article

Submit your next manuscript at $>$ springeropen.com 